\title{
Fabrication and Performance Evaluation of Integrated Solar- Driven Membrane Distillation System with Serpentine-shape of Flat Plate Solar Collector for Seawater Desalination
}

\author{
M. A. H. M. Hanoin, N. S. Mohammed, M. A. I. Z. Arris, A. I. A. Bakar, N. M. \\ Mokhtar*, A. A. Razak \\ Faculty of Engineering Technology, Universiti Malaysia Pahang, Lebuhraya Tun \\ Razak 26300 Kuantan, Pahang, Malaysia
}

Submitted: 29/05/2019. Revised edition: 9/07/2019. Accepted: 11/07/2019. Available online: 20/09/2019

\begin{abstract}
Solar-powered membrane distillation (SPMD) system has gained its popularity in desalination application for past decade credit to the system efficiency in producing pure water and the utilization of renewable energy. However, most of the past SPMD works used commercial solar thermal collector (STC) as the thermal energy supply to the feed solution and the study only focused on the performance of the system in terms of flux and salt rejection. In this work, a self-made flat plate solar collector (FPSC) with the serpentine-shape pipe was designed and fabricated to study the effect of the STC towards the membrane performance. Before testing, a simulation work of the fluid flow inside the serpentine-shape pipe of the FPSC was analyzed using NX 10.0 computer-aided design simulation. After that, the efficiency of the self-made FPSC system was tested directly to sunlight in order to identify the maximum irradiance and the temperature of the feed solution. Due to the fluctuation of solar irradiance, the experimental setup of the SPMD system was tested using a solar simulator, and the performance was compared with the membrane distillation (MD) system without integration with FPSC system. Based on the simulation data, it can be concluded that the heat losses across the pipe are due to the slower fluid velocity and sudden pressure drop, which attributed to centripetal force and pressure differences. Meanwhile, the outdoor evaluation data showed that the temperatures of collector and water inside the feed tank could reach up to $84^{\circ} \mathrm{C}$ and $64^{\circ} \mathrm{C}$, respectively when the maximum irradiance of $938 \mathrm{~W} / \mathrm{m} 2$ was applied. For the performance evaluation between with and without the self-made FPSC system, it can be seen that only marginal difference can be observed for the permeate flux and salt rejection with an average difference of $6.06 \%$ and $1.29 \%$, respectively.
\end{abstract}

Keywords: Solar-powered membrane distillation, flat plate solar collector, membrane distillation, desalination, integrated system

\subsection{INTRODUCTION}

Since the 1980s, the demand for water use is increasing by $1 \%$ per year due to the increasing population, urbanization, and industrialization [13]. Around 3.7 billion people are currently affected by water scarcity claimed by the United Nations World Water Development Report. In 2050, this number could increase up to 5.7 billion. Besides, the domestic water source for populations in remote areas is supplied from the underground water, like brackish water. It is a kind of water that consists of a mixture between saltwater and freshwater, typically includes a high level of dissolved salts. In order to make this water drinkable, an efficient method called a desalination process was developed to remove salt from the brackish water and seawater. One of the potential desalination technologies 
to compensate for the shortage of freshwater is known as membrane distillation (MD) process [4-9]. It is a thermally driven separation process which only allows vapour molecules to pass through the porous hydrophobic membrane. However, the conventional MD system was $100 \%$ dependable on electricity from a grid. The electricity is generated from a power plant that mostly burns fossil fuels, which cause pollution and raises electricity cost.

In this regard, the solar-powered membrane distillation (SPMD) system was introduced to overcome the issues confronted by the MD system. SPMD can be reviewed as a "green" and sustainable desalination technology due to the integration with a low-grade and renewable energy source such as solar energy. It can be proved by utilizing renewable energy sources in the desalination process will reduce the environmental problems, keep conventional energy to be applied to other applications, sustainable and low-maintenance energy source [10]. The SPMD system can be explained structurally as integration between the MD system and solar technologies [11-16]. These solar technologies comprise solar thermal collector (STC) and solar photovoltaic (PV) collector. The STC transforms solar radiation into heat to drive the phase-change processes, while solar PV panel transforms solar radiation into electricity to generate electrical device. Generally, solar collectors comprised of concentrating and non-concentrating collectors [17-20]. MD system can be coupled with both types of STC. Coupling with non-concentrating collectors is typically utilized for small-scale and remote areas, whereas concentrating collector was utilized for large scale. At present, commercialization of concentrating collectors has significantly raised since the past decade. However, a concentrating collector plant integrated desalination technology required high cost and electricity demand to drive the operation. Thus, the selection of STC types for integrating with the MD system depends on different scene and requirement.

Since the study area focusing on remote areas, this study emphasizes on the integration of the MD system with non-concentrating STC. Thus, the research will be using a flat plate solar collector (FPSC) as non-concentrating STC. FPSC is known as the conventional solar energy-exploiting device and foundation of domestic solar water heating worldwide which was designed and used in a wide range of forms such as established in residential and office buildings because of high thermal efficiency and reliable performance. Another key advantages of these FPSCs are their low cost, durability, simple design, and manufactured efficiently. One of the vital components of the FPSC is the absorber section as to how well the solar radiation absorbed and converted into the thermal energy. There are various sorts of STC that can be exploited to transform solar radiation into heat. This is usually done by employing a heat transfer fluid; typically, a fluid (water, synthetic fluids or oil) in a receiver tube (absorber) to absorb the solar radiation in the form of thermal energy whereas the energy is circulated throughout the collector. Fundamentally, the FPSC system utilizes a copper pipe with serpentine-shape bonded or clipped to a conductive absorbing plate with a spectrally selective black coating. A copper pipe was chosen due to high conductivity material. Previous studies for FPSC design with the serpentineshape pipe at the absorber section has been investigated independently without integrates with MD system [21-23]. The proposed serpentine- 
shape pipe FPSC design is believed reliable to provide enough thermal energy through the MD system. Due to that, numerous research has been done regarding integrated the FPSC with the MD system and most of them are using commercial FPSC system [21, 24-26].

In this work, a self-made FPSC has been established, and the effect of the fabricated FPSC through MD system has been investigated. Moreover, the thermal performance analysis on the serpentine-shape absorber section of FPSC towards MD system by using computer-aided design software has been simulated. Extensive research regarding the simulation and experimental setup on the performance of the flat panel collector has been studied [22, 27-28]. An outdoor evaluation for FPSC was investigated to identify the optimum solar radiation that can provide thermal energy into the feed tank, then implemented on the solar simulator for SPMD performance evaluation. The research also intends to compare separation performance between the MD system with and without the FPSC system in terms of permeate flux and salt rejection.

\subsection{MATERIAL AND METHODS}

\subsection{Material}

Table 1 shows the list of materials that have been used for the FPSC system. While to support the MD system, materials needed to fabricate the hollow fiber membranes include the polymer pellets and solvent. A commercial polyvinylidene fluoride (PVDF) polymer $($ Kynar® $760, \mathrm{MW}=$ $440,000 \mathrm{~g} / \mathrm{mol}$ ) was purchased from Arkema Inc., Philadelphia, USA and employed as the base polymer. Nmethyl-2-pyrrolidone (NMP) with the purity of more than $99.5 \%$ was purchased from Merck and used as a solvent without further purification.
Salt, sodium chloride $(\mathrm{NaCl}, \mathrm{MW}=$ $58.44 \mathrm{~g} / \mathrm{mol}$ ) supplied by Merck was used to prepare the simulated seawater by dissolving it in deionized water produced by ELGA Micromeg Deionizer.

Table 1 Materials selection for the FPSC system

\begin{tabular}{|c|c|}
\hline Materials & Characteristics \\
\hline Copper pipe & 3/8-inch (Outer diameter) \\
\hline $\begin{array}{l}\text { Polypropylene } \\
\text { container }\end{array}$ & $350 \mathrm{~mm} \times 480 \mathrm{~mm}$ \\
\hline Aluminium plate & $1 \mathrm{~mm}$ (thickness) \\
\hline Rubber foam & 14mm (thickness) \\
\hline Stainless-steel tank & $500 \mathrm{ml}$ (volume) \\
\hline $\begin{array}{l}\text { Mild steel hollow } \\
\text { (square hollow } \\
\text { section, SHS) }\end{array}$ & $25 \mathrm{~mm} \times 25 \mathrm{~mm} \times 2 \mathrm{~mm}$ \\
\hline $\begin{array}{l}\text { Universal } \\
\text { transparent PVC } \\
\text { pipe tube }\end{array}$ & 3/8-inch (Outer diameter) \\
\hline
\end{tabular}

\subsection{Fabrication and Performance Evaluation of FPSC System}

FPSC was fabricated in this work as STC system to integrate with the MD system. Figure 1 shows the FPSC design of a three-dimensional and real image, respectively. The system comprises of absorber section, housing, and heat exchanger section. The absorber section structurally consists of a glass cover, aluminium absorber plate, a copper pipe, a thermal insulation layer made of rubber foam and polypropylene framework. The insulation layer has minimized heat losses at side and back of the collector. Also, the solar absorbing area is 0.168 $\mathrm{m}^{2}$. An absorber plate has the potential to transfer the collected energy to the working fluid with a less temperature drop due to high thermal conductivity. This FPSC is an active system; thus, a $12 \mathrm{~V}$ direct current (DC) water pump was installed so that the heat transfer fluid will circulate throughout the system. Water was used as the heat transfer fluid. This system consists 
only one loop that will re-circulated until reached the maximum temperature. A mild steel hollow was fabricated for the housing of FPSC system, as shown in Figure 1. A copper pipe was bent into two design with different section; serpentine-shape for absorber section, and helically-shape on the heat exchanger. The serpentineshape maximizes the surface area in order to collect solar radiation. This designed copper pipe was attached to the absorber plate, and heat transfer fluid was heated as it flows in the tubes by absorbing heat from the absorber plate. A copper pipe designed as a helically-shape was inserted into a stainless-steel tank. This helicallyshape used to transfer the thermal energy on the heat exchanger section.

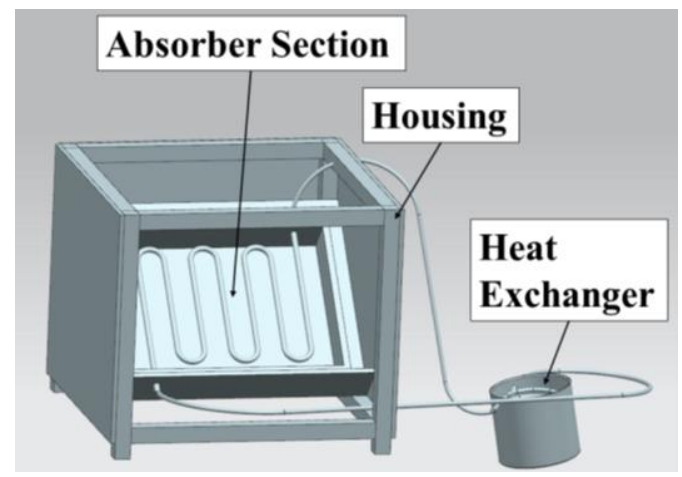

(a)

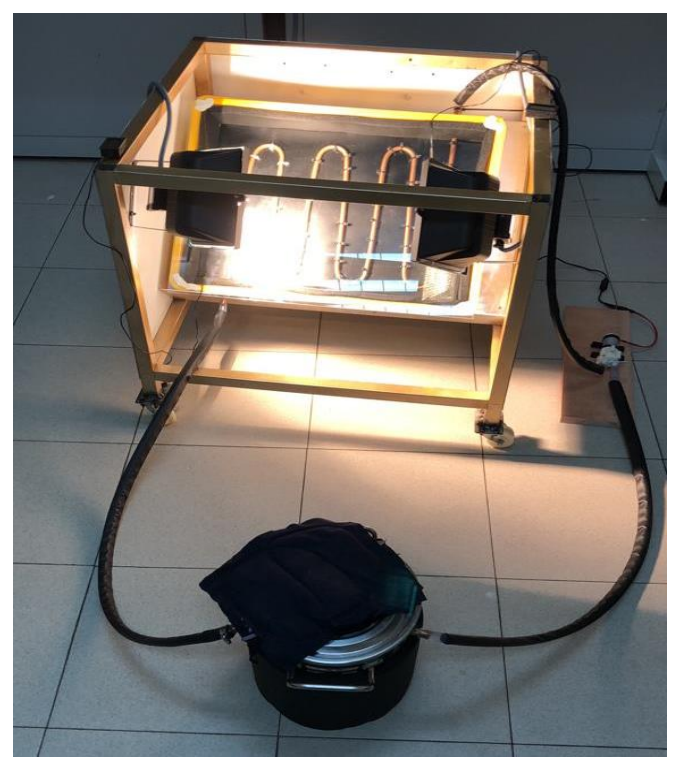

(b)

Figure 1 (a) Three-dimensional image versus (b) real image of FPSC design
The energy conversion process of the FPSC is stated as the following procedures: (1) Solar radiation reaches the absorber surface and turns into thermal energy, (2) The generated thermal energy transfers to the solar loop working fluid, (3) The heat transfer fluid will transmit the thermal energy into MD unit through feed tank as a heat exchanger section.

For the simulation study, a copper pipe with serpentine-design was investigated to find out the feasibility of the proposed design as an absorber by using computer-aided design simulation NX 10.0. A simulation was done based on the several parameters such as fluid velocity, temperature flow, and the pressure drop in the copper pipe which located inside the solar collector. In this simulation, the dimension and number of turns for the serpentine-shaped copper tube were simulated based on the original fabricated design.

In order to test the efficiency of the fabricated FPSC system, the experimental setup has been conducted outside of the building. Whereas, the FPSC system was operated on a sunny day from 11:00 to 17:00 (about 6hours operation). The experiment was carried out at Universiti Malaysia Pahang, located at Gambang, Pahang, Malaysia $\left(3.7185^{\circ} \mathrm{N}, 103.1208^{\circ} \mathrm{E}\right)$. The evaluation was operated with several parameters such as solar radiation, and temperature at both collector and water in the feed tank. The selected solar radiation was obtained with respect to the temperature at the absorber section of the FPSC and water in the feed tank, which will be implemented for the SPMD performance evaluation. 


\subsection{Integration of FPSC with MD System}

Before integrating the system, the PVDF hollow fiber membrane was fabricated in the laboratory using a dry-jet wet spinning method. Prior to the dope solution formulation, the polymer pellets were desiccated in a vacuum oven at $60 \pm 2^{\circ} \mathrm{C}$ for more than 24 hours to eliminate moisture content. The spinning dope including 12 wt.\% PVDF and 80 wt.\% NMP were set up throughout homogeneous stirring of the mixture at temperature $60^{\circ} \mathrm{C}$ and stirring rate approximately $450 \mathrm{rpm}$ for several hours. Then, the dopes were degassed to eliminate air bubbles before the spinning process. The spinning conditions of each parameter employed in this work are also outlined in Table 2, whereas the particular description of the spinning process can be revealed in previous work [29]. After spinning, the spun fibres were submerged in water for a few days to eliminate residual solvent. The morphology of the membrane sample was examined using a scanning electron microscope (SEM) (TM-3000, Hitachi), as shown in Figure 2.

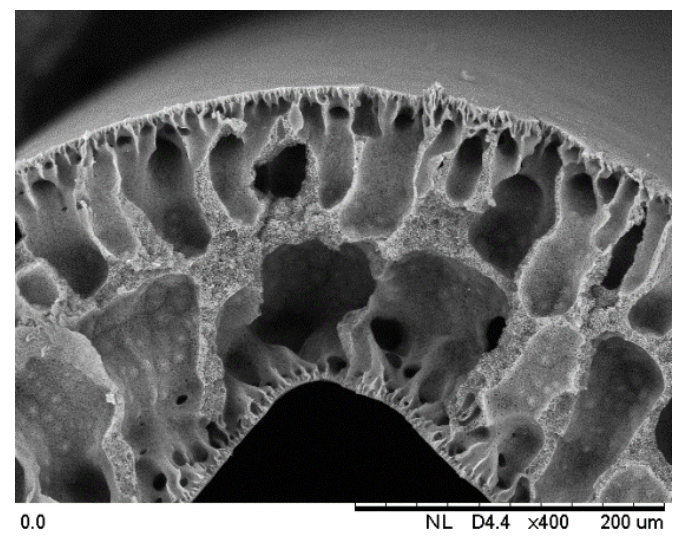

Figure 2 Partial cross-section of the fabricated PDF membrane

The SPMD system consists of two integrated sub-systems: the self-made FPSC and the MD unit. Fundamentally, the FPSC system was used to provide the thermal energy into the hot solution of the MD system. On the other hand, the MD system consists of two different solutions with different temperature (hot and cold solution). Figure 3 shows a schematic diagram of the fully integrated SPMD system. In this research study, a self-made FPSC with the serpentine-shape on absorber section was developed. The effectiveness of the FPSC was studied by maintaining the temperature of simulated seawater in the feed tank and evaluating the performance of the SPMD in desalination process as compared to the conventional MD system.

Table 2 PVDF hollow fiber spinning conditions

\begin{tabular}{ll}
\hline Spinning conditions & Value \\
\hline $\begin{array}{l}\text { Bore fluid flow rate } \\
(\mathrm{ml} / \mathrm{min})\end{array}$ & 2.0 \\
$\begin{array}{l}\text { Dope extrusion rate } \\
(\mathrm{ml} / \mathrm{min})\end{array}$ & 4.0 \\
$\begin{array}{l}\text { Bore fluid } \\
\text { Spinneret OD/ID }\end{array}$ & $\begin{array}{l}\text { DI water } \\
(\mathrm{mm} / \mathrm{mm})\end{array}$ \\
$\begin{array}{l}\text { Air gap distance }(\mathrm{cm}) \\
\text { Spinning dope temperature } \\
\left({ }^{\circ} \mathrm{C}\right)\end{array}$ & 0 \\
$\begin{array}{l}\text { External coagulation } \\
\text { temperature }\left({ }^{\circ} \mathrm{C}\right)\end{array}$ & 25 \\
\hline
\end{tabular}

For the SPMD experimental setup, the fabricated system was operated inside the building by replacing the solar radiation from the sun with a solar simulator. This solar simulator attached to the FPSC body system to make it more portable, as shown in Figure 1 (b). The irradiance emitted directly to the absorber section. The solar simulator is a system that capable of controlling a light source with intensity level and spectral composition such as sunlight, usually conducted in an isolated location, 
especially inside the building [30]. There are various light source/lamp types for the solar simulator, including argon arc, tungsten halogen, metal halide, xenon arc, and light-emitting diode (LED) lamps [31]. The selection of the solar simulator depends on the system output requirements, characteristics and availability of light source output spectrum, and field of application. The solar simulator used in this experiment is a tungsten halogen lamp. It can be noted that this type of incandescent lamp is widely used in solar thermal application as less spectrum-sensitive characteristics [30].

\section{Solar Radiation}

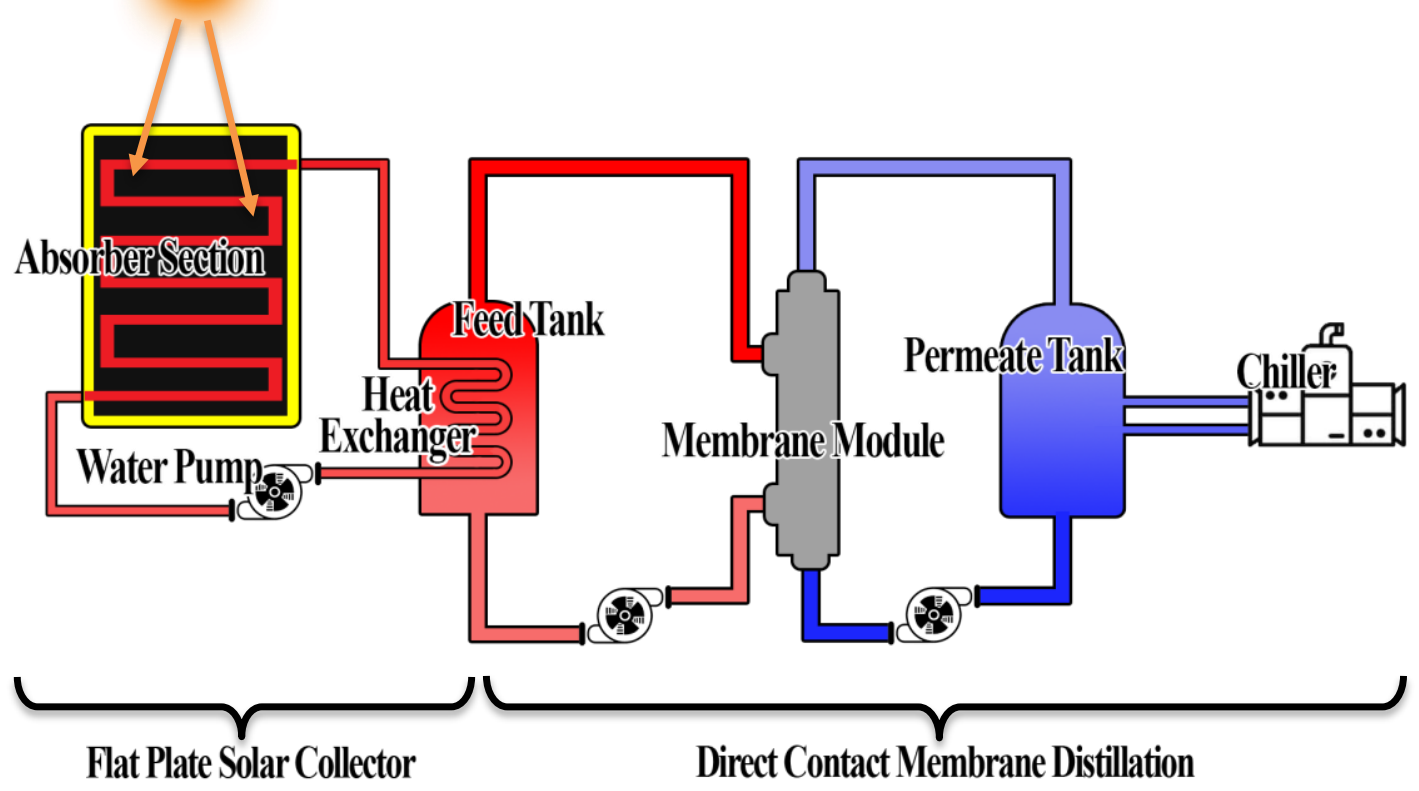

Figure 3 Schematic flow diagram of the lab-scale SPMD system

The correlation between outdoor FPSC system and SPMD experiment was to acquire the selected data. The outdoor evaluation cannot give the best performance due to the intermittent effect of the input parameters such as solar radiation that is inconsistent. Therefore, the purpose of an outdoor evaluation is to obtain the solar radiation data with respect to the temperature on FPSC and water in the feed tank. After that, the selected solar radiation will be implemented in the SPMD performance experiment. The solar simulator was adjusted by selecting solar radiation data obtained from the outdoor evaluation. To operate the proposed SPMD evaluation, the estimated time given is around 2hours. This experiment was focusing on the comparison of the performance between the conventional MD and SPMD system.

A stainless-steel module with a diameter of $3 / 8$ inch was utilized to identify the separation performance of the developed membranes. The experiments were carried out at feed and permeated temperatures of $60 \pm 1^{\circ} \mathrm{C}$ and $20 \pm 1{ }^{\circ} \mathrm{C}$, respectively. The most important characteristics in determining membrane performance are rejection and flux. The theory of pollutants' rejection and mass transfer analysis has been performed in order to evince the considerable impact of 
membrane permeability upon the mass transfer (permeate flux). The permeate flux is known as distillate flux, and mass flux $(\mathrm{J})$ can be defined as the amount of water transferred across a unit membrane area in a unit of time. The permeate flux, $J$, of the membrane $\left(\mathrm{kg} \mathrm{m}^{-2} \mathrm{~h}^{-1}\right)$ was fixed using Equation (1).

$$
J=\frac{\Delta W}{A \Delta t}
$$

where $\Delta W(\mathrm{~kg})$ is the weight of permeate gathered over a predetermined time $\Delta t(\mathrm{~h})$ of process and $A\left(m^{2}\right)$ is the effective membrane area and calculated as $n \pi d_{o} L$. To determine salt rejection, the rejection rate $(\mathrm{R} \%)$ of the membrane is calculated using Equation (2).

$$
R(\%)=\left(1-\frac{C_{p}}{C_{f}}\right) \times 100
$$

where $C_{p}$ and $C_{f}$ are the $\mathrm{NaCl}$ concentration $(\mathrm{g} / \mathrm{L})$ in bulk permeate and feed solution.

\subsection{RESULTS AND DISCUSSION}

\subsection{Simulation Results}

The simulation analysis was conducted by considering several parameters, which are fluid velocity, total pressure, and thermal energy distribution on the copper pipe. As can be seen in Figure 4, the simulation was done for the velocity of the fluid inside the copper pipe. The velocity of the fluid entering the tube at a volume flow rate of 1000 L per hour was graphically expressed. The result shows that the velocity of the fluid located at the inlet is the fastest compared to the other location in the pipe. The simulation also showed that the velocity begins to decrease when the fluid past through the serpentine sections. The fluid will lose its momentum after the obstacles. The viscosity of the fluid influences the fluid to imitate the shape of the tube, and when it reaches the curve, the streamline will be thinner to the wall of the tube. The velocity normalized when it passed the curve due to the centripetal force exist with the pressure difference inside and outside of walls of the tube. In term of thermal energy harvesting on the copper pipe, it can be predicted that high heat transfer can be transported to the fluid inside the copper pipe when the fluid velocity is low. This is because solar radiation can interact in a more extended period to the solar collector during a slow flow rate.

The pressure simulation shows that serpentine-shape will give a pressure drop from the inlet to the outlet of the tube, as illustrated in Figure 5. This occurrence can be correlated to the frictional force between the fluid and the wall of the tube that could cause resistance to the flow of the fluid. The pressure drop also was affected by the friction loss when the fluid passes through the curves. The excessive pressure drop will lead to poor system performance and directly contribute to excessive energy consumption. 


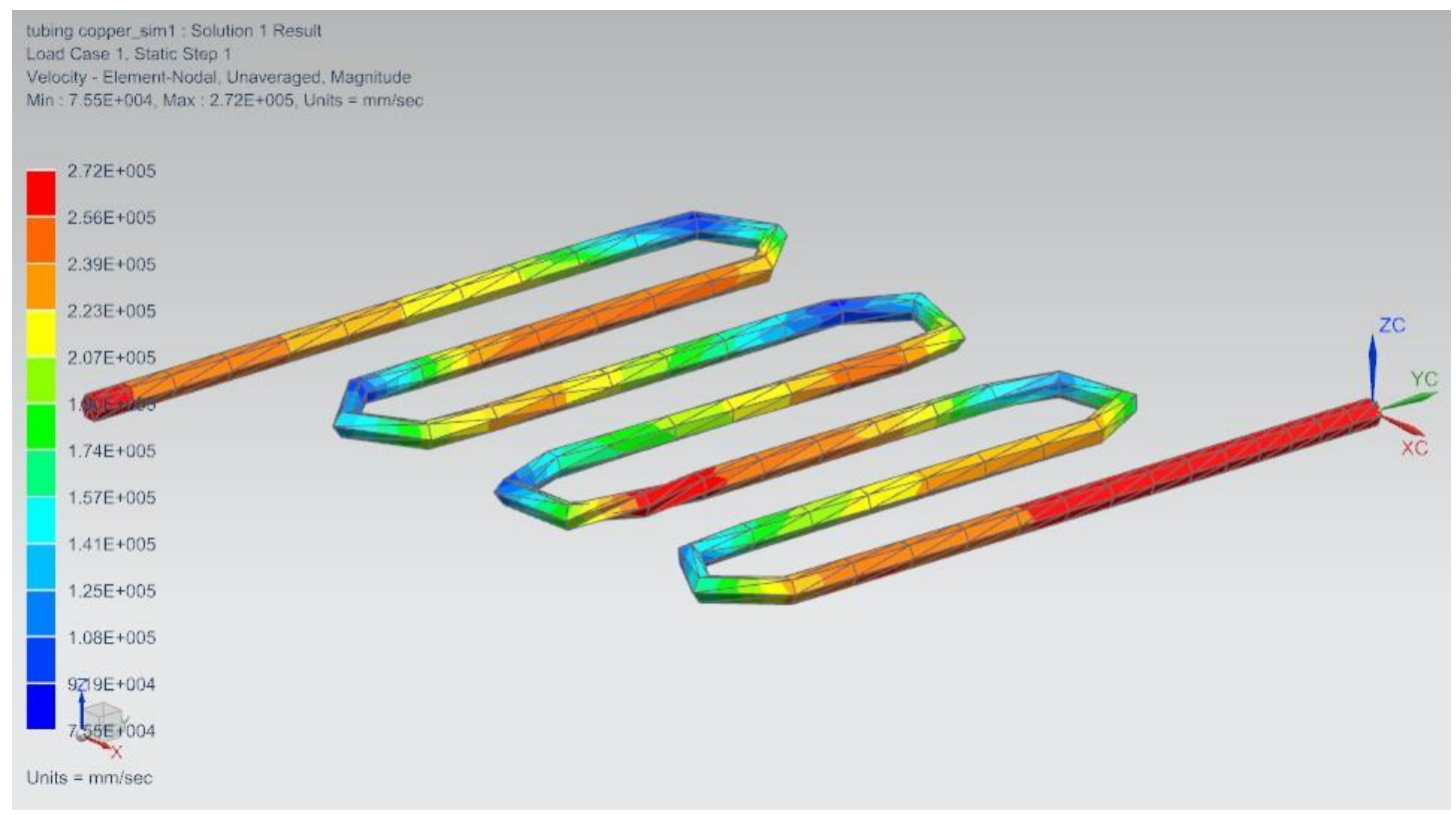

Figure 4 The fluid velocity of the simulation

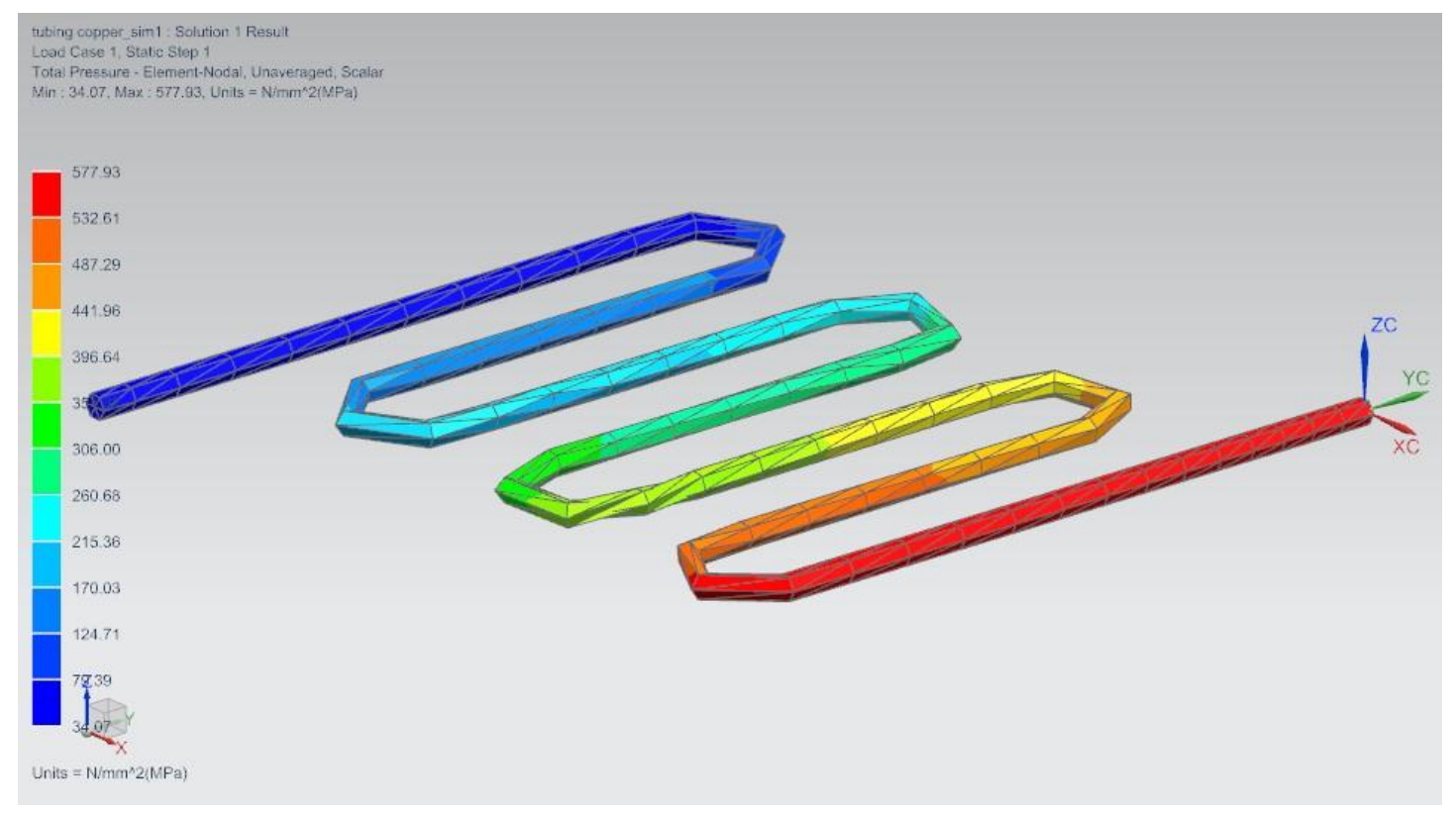

Figure 5 The total pressure of the simulation

The temperature of the fluid increased as it approaches the outlet of the pipe, as shown in Figure 6. This is due to the solar collector's behaviour and performance by gaining heat from the solar radiation, and the copper tube that transferred the heat gained efficiently. The pressure drop also affects the temperature of the fluid since the slower the fluid flows in the tube; the higher heat could be gain from the trapped irradiation heat in the collector and through the conductive heat received from the absorbing plate under the copper tube. However, some heat loss may be occurred due to the frictional force of the serpentine-shape design. 


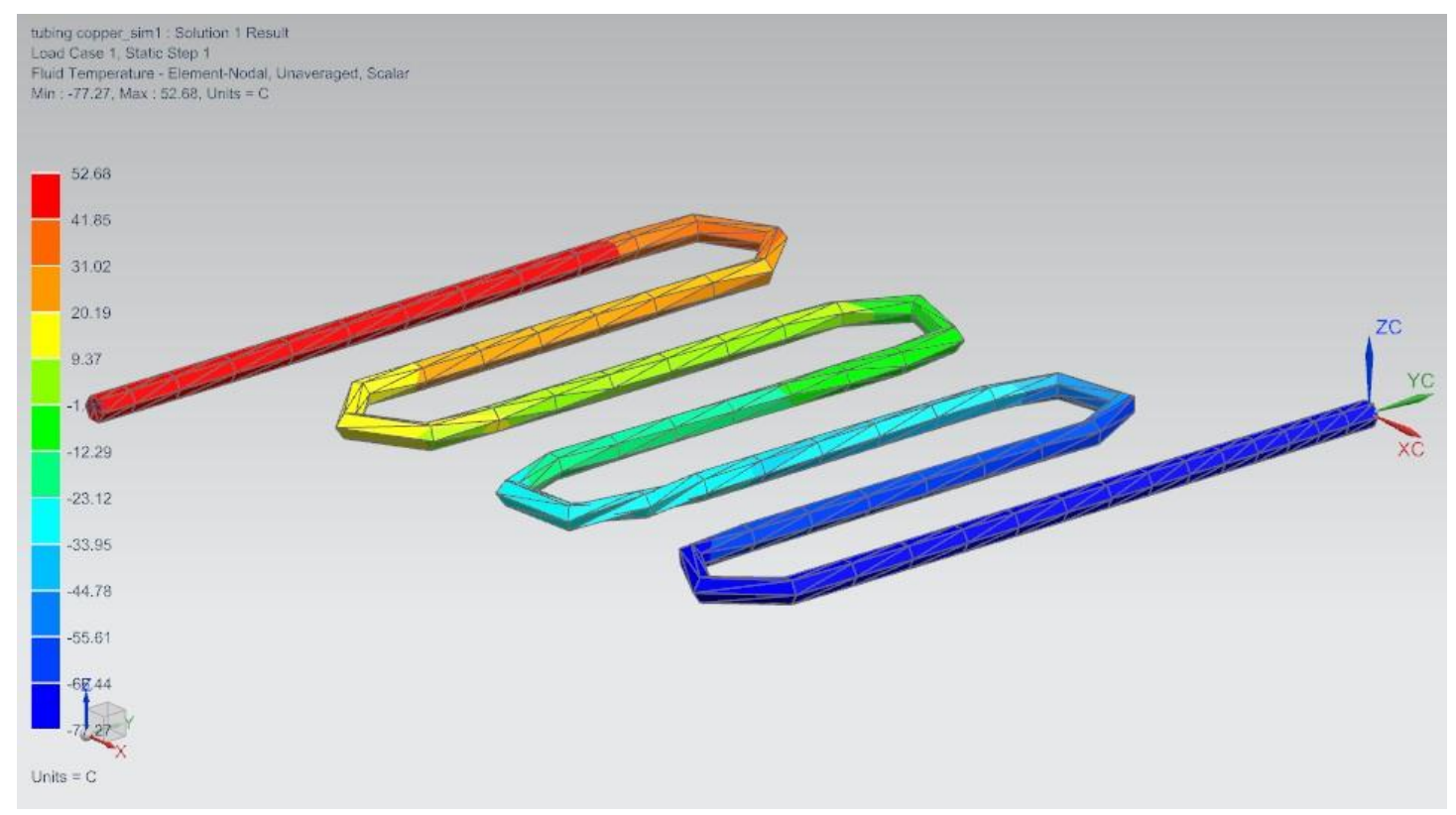

Figure 6 Thermal energy harvesting simulation on copper pipe

\subsection{Outdoor Evaluation of the Fabricated FPSC System}

Figure 7 shows the temperature of bulk water (represent feed solution) inside the coiled feed tank and the temperature of the fabricated FPSC for the solar radiation from the direct sunlight. The temperature inside the feed tank relies on the rate of the heat transfer supplied by the FPSC. The higher the efficiency of the fabricated FPSC, the higher the water temperature inside the feed tank that can be reached. As the peak of the irradiance reached $938 \mathrm{~W} / \mathrm{m}^{2}$, the FPSC temperature could increase up to $84^{\circ} \mathrm{C}$, while water temperature inside the feed tank was recorded $64^{\circ} \mathrm{C}$. It can be noted in Figure 7, while the irradiance of sunlight continuously rises, the temperatures at the FPSC and the feed tank were slightly increased. Also, when the irradiance starts to escalate down, vice versa trend could be observed. This is due to heat loss occurred during that time and difficulties to escalate up to the desired temperature. The pattern of temperature fluctuation at the fabricated FPSC slightly follows the solar radiation pattern compared to the water temperature inside the tank. It can be deduced that heat loss is more massive at the FPSC section compared to the feed tank, mainly due to the heat losses to the surroundings and air resistance effect.

The data of the thermal distribution on serpentine-shape copper pipe (absorber section FPSC) obtained from CFD simulation can be related in this experimental result. This can be proved from the previous simulation data as the serpentine-shape affect the most heat loss on FPSC compared to the water at the feed tank. As the radiation starts to escalate down, there is less irradiance to emits on the FPSC. Therefore, due to fluid continuously to past through the copper pipe, the heat from the FPSC begin to lose into the surrounding. 


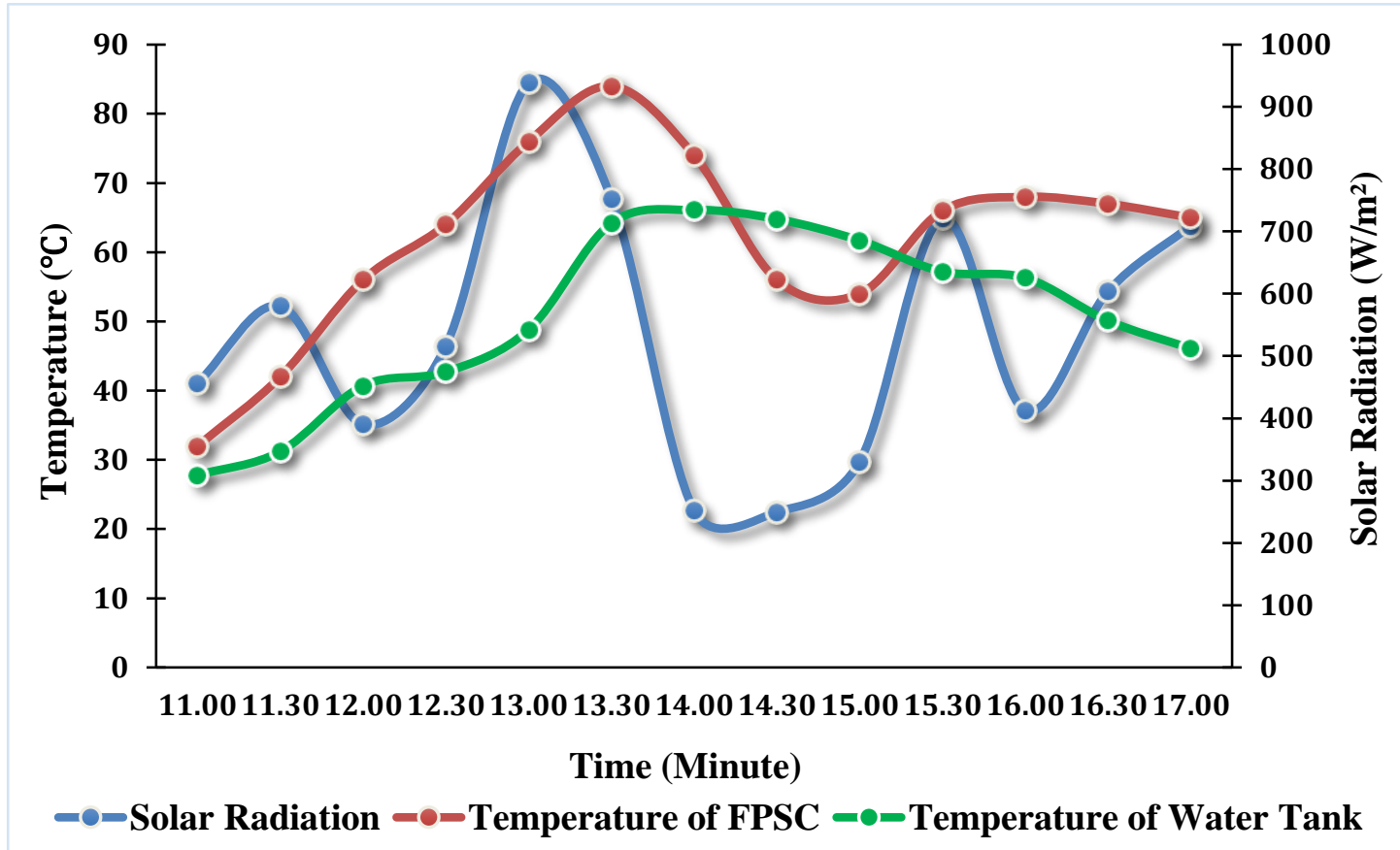

Figure 7 Temperatures of water inside the feed tank and on the FPSC versus solar radiation

\subsection{Performance Evaluation of the Fabricated FPSC System}

\subsubsection{Permeate Flux Versus Time}

The permeate flux results between MD and SPMD systems were compared in Figure 8. The MD system using the electrical heater was set with a temperature of $60^{\circ} \mathrm{C}$ along the 2 hours of analyzation. The total mass obtained after 2 hours for temperature difference was $100.83 \mathrm{~g}$, and the maximum permeate flux was $4.30 \mathrm{kgm}^{-2} \mathrm{~h}^{-1}$ at 120 minutes. For the SPMD system, the result showed that the distillate mass also increases. The total mass obtained after 2 hours for temperature difference was $98.83 \mathrm{~g}$, and the maximum permeate flux was $4.22 \mathrm{~kg} \mathrm{~m}^{-2} \mathrm{~h}^{-1}$ at 120 minutes. As a result, there are only slightly different permeate flux between MD and SPMD system with an average difference of $6.06 \%$. The permeate flux for SPMD is lesser compared to MD due to the inconsistent temperatures since the heat depends on the solar radiation by the FPSC system. Besides, the feed temperature has a strong influence on permeate flux [32]. The higher temperature difference between hot and cold solution, the higher flux can be obtained. The separation occurs as a result of phase change arising from the partial vapour pressure difference between the feed and receiving phase.

\subsubsection{Salt Rejection Versus Time}

The salt rejection of the MD system and SPMD system were presented in a line graph in Figure 9. The salt rejection for both MD and SPMD system shows almost similar performance, which recorded more than $85 \%$ salt rejection and average difference with only $1.29 \%$. Although the salt is considered non-volatile compound, the $\mathrm{NaCl}$ detection in the permeate tank can be attributed by the inefficiency of the fabricated PVDF membrane. This phenomenon is common when the membrane is prone 
to pore wetting and scaling [33]. Apart of these results, it can be highlighted that the FPSC system does not affect the quality of the product as the main target of integrating the FPSC with the MD system is to provide thermal energy to the feed solution.

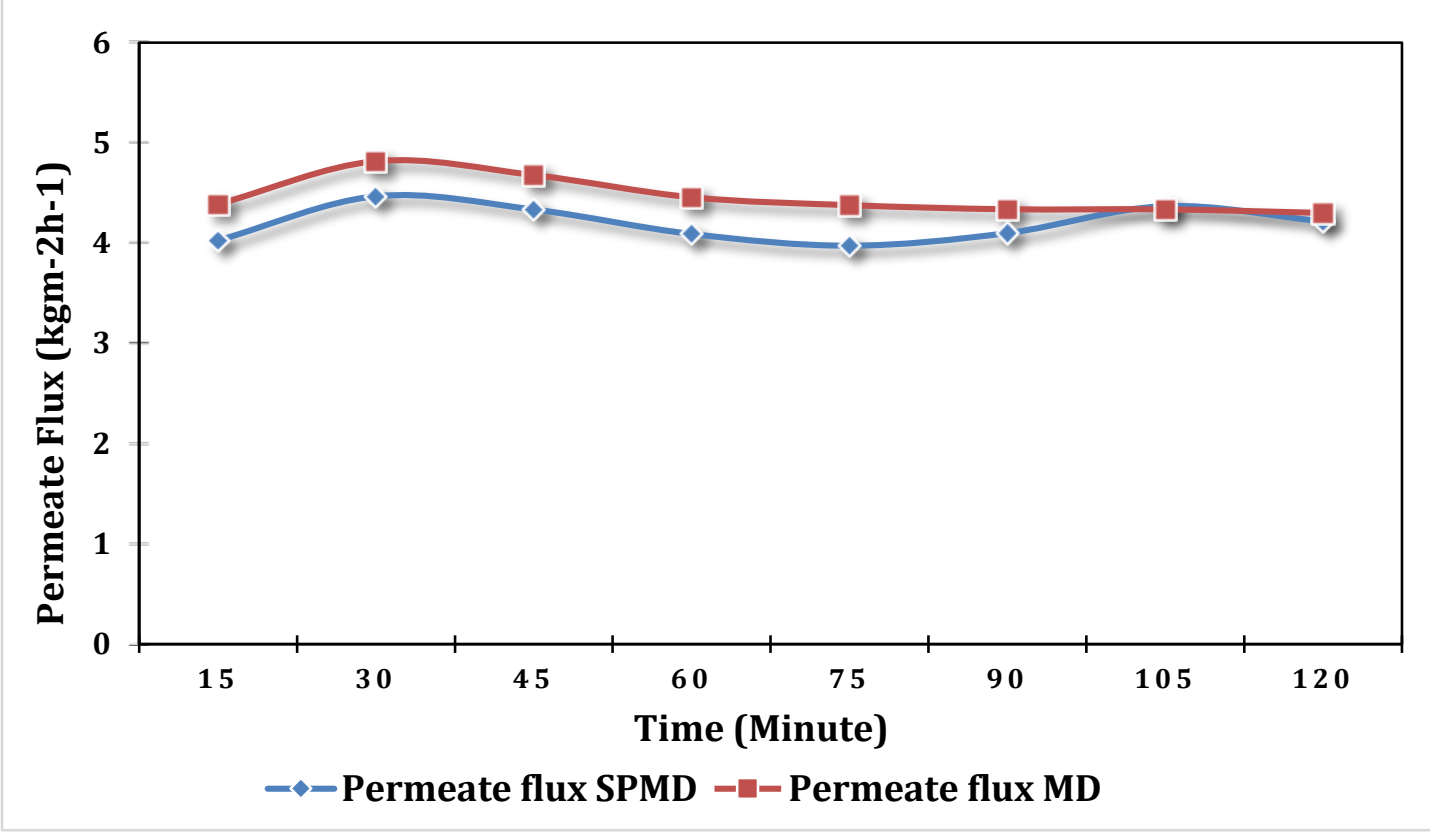

Figure 8 Permeate flux versus time

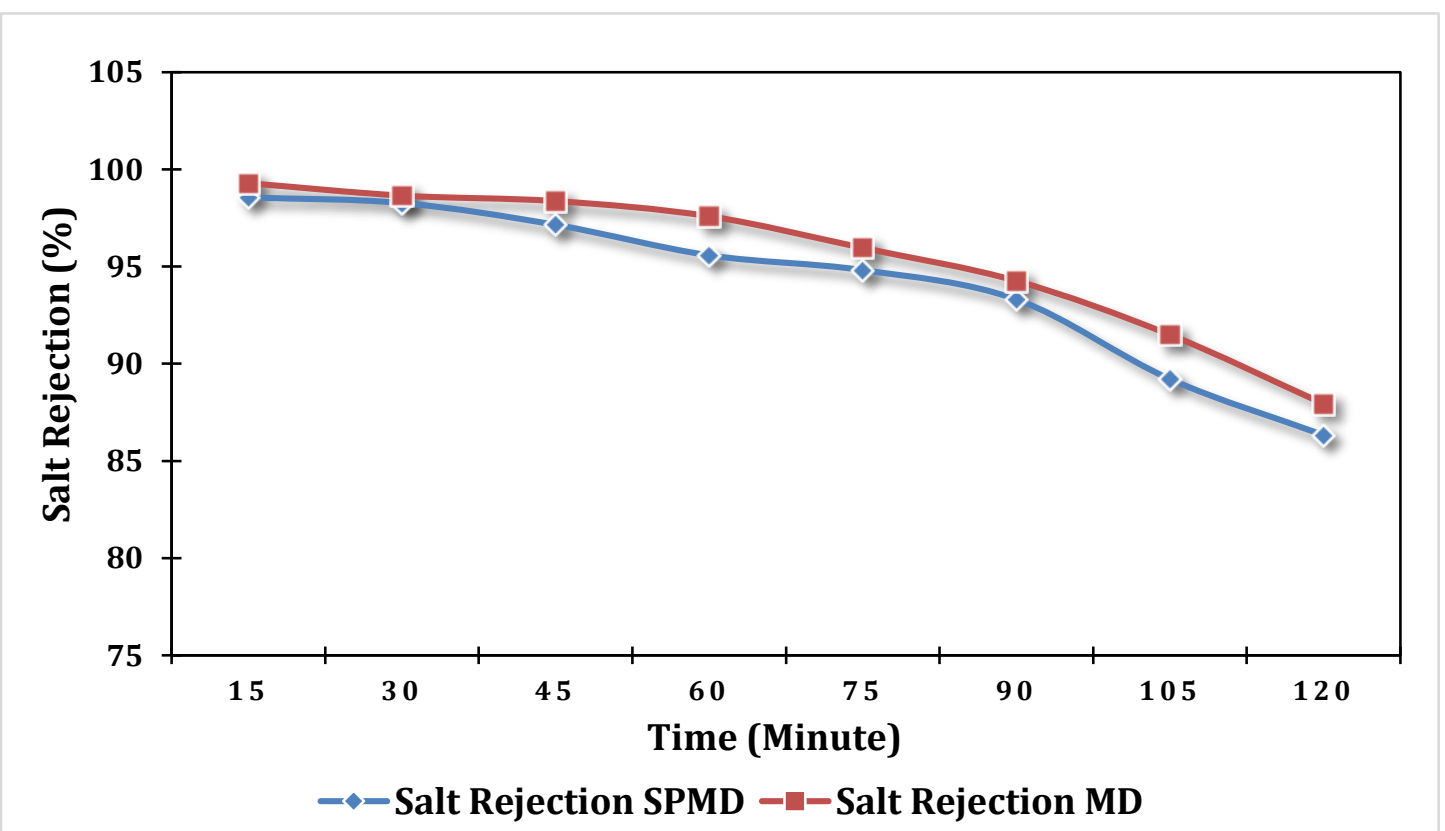

Figure 9 Salt rejection versus time 


\subsection{CONCLUSION}

As a promising alternative to replace other separation processes, MD has gained much interest for its lower operating temperature and pressure, lower energy requirement than conventional distillation and higher rejection rate than in pressure driven process. However, the conventional MD using $100 \%$ of electricity from grid supply that will cause pollution and raise electricity cost. SPMD was introduced to overcome the issues confront by MD system. A hybrid system consisted of newly fabricated FPSC, and MD system was proposed for this experiment to evaluate the thermal performance. The simulation analysis for the serpentine-shape design on the absorber section of the FPSC system was also being investigated. As a result, the simulation showed:

- The fluid velocity at the inlet pipe is faster than the outlet pipe due to the centripetal force exist.

- Pressure drops occur inside the copper pipe due to the pressure difference.

- High thermal energy can be gained in the fabricated FPSC due to the low fluid velocity; however, the thermal energy was compensating with the heat loss caused by the frictional force of the curve design serpentine-shape.

For the outdoor evaluation, the temperature at FPSC has higher heat losses compared to the water temperature inside the feed tank as proved on simulation data due to the curve flow of serpentine-shape. In SPMD performance evaluation, the result showed that the proposed SPMD system has marginal different from the conventional MD system.

The key findings are enumerated as below:
- An innovative proposed SPMD system of integration between a self-made serpentine-shape pipe FPSC design through the MD system.

- Due to marginal different performance between the proposed SPMD system and conventional MD system, the SPMD system is reliable to compensate for freshwater issues without increasing the electricity cost and pollution

\section{ACKNOWLEDGEMENT}

The authors gratefully acknowledge the Ministry of Education (MOE) for financial support via Fundamental Research Grant Scheme (FRGS) (Vote No: RDU170118) and support from Universiti Malaysia Pahang via internal grant (Vote No: RDU170315).

\section{REFERENCES}

[1] M. A. E. R. Abu-Zeid, Y. Zhang, H. Dong, L. Zhang, H. L. Chen, and L. Hou. 2015. A Comprehensive Review of Vacuum Membrane Distillation Technique. Desalination. 356: 114.

[2] D. González, J. Amigo, and F. Suárez. 2017. Membrane Distillation: Perspectives for Sustainable and Improved Desalination. Renewable and Sustainable Energy Reviews. 80: 238-259.

[3] Q. Chen, Y. Li, and K. J. Chua. 2016. On the Thermodynamic Analysis of a Novel Low-grade Heat Driven Desalination System. Energy Convers. Manag. 128: 145-159.

[4] L. M. Camacho, L. Dumée, J. Zhang, J. D. Li, M. Duke, J. Gomez, and S. Gray. 2013. 
$\begin{array}{llr}\text { Advances in } & \text { Membrane } \\ \text { Distillation } & \text { for } & \text { Water }\end{array}$

Desalination and Purification

Applications. Water

(Switzerland). 5: 94-196.

[5] M. Khayet and T. Matsuura. 2011. Membrane Distillation Principles and Applications. Elsevier.

[6] A. Alkhudhiri, N. Darwish, and N. Hilal. 2012. Membrane Distillation: A comprehensive Review. Desalination. 287: 2-18.

[7] E. Drioli, A. Ali, and F. Macedonio. 2015. Membrane Distillation: Recent Developments and Perspectives. Desalination. 356: 56-84.

[8] R. Schwantes, A. Cipollina, F. Gross, J. Koschikowski, D. Pfeifle, M. Rolletschek, and V. Subiela. 2013. Membrane Distillation: Solar and Waste Heat Driven Demonstration Plants for Desalination. Desalination. 323: 93-106.

[9] M. Khayet. 2011. Membranes and Theoretical Modeling of Membrane Distillation: A Review. Adv. Colloid Interface Sci. 164: 56-88.

[10] F. Nematollahi, A. Rahimi, and T. T. Gheinani. 2013. Experimental and Theoretical Energy and Exergy Analysis for a Solar Desalination System. Desalination. 317: 23-31.

[11] J. Koschikowski, M. Wieghaus, M. Rommel, V. S. Ortin, B. P. Suarez, and J. R. Betancort Rodríguez. 2009. Experimental Investigations on Solar Driven Stand-alone Membrane Distillation Systems for Remote Areas. Desalination. 248: 125131.

[12] R. G. Raluy, R. Schwantes, V. J. Subiela, B. Peñate, G. Melián, and J. R. Betancort. 2012. Operational Experience of a
Solar Membrane Distillation Demonstration Plant in Pozo Izquierdo-Gran Canaria Island (Spain). Desalination. 290: 1-13.

[13] H. E. S. Fath, S. M. Elsherbiny, A. A. Hassan, M. Rommel, M. Wieghaus, J. Koschikowski, and M. Vatansever. 2008. PV and Thermally Driven Small-scale, Stand-alone Solar Desalination Systems with Very Low Maintenance Needs. Desalination. 225: 1-3.

[14] T. C. Chen and C. D. Ho. 2010. Immediate Assisted Solar Direct Contact Membrane Distillation in Saline Water Desalination $J$. Memb. Sci. 358: 122-130.

[15] F. Banat, N. Jwaied, M. Rommel, J. Koschikowski, and M. Wieghaus. 2007. Performance Evaluation of the "large SMADES" Autonomous Desalination Solar-driven Membrane Distillation Plant in Aqaba, Jordan. Desalination. 217: 17-28.

[16] E. K. Summers and J. H. Lienhard. 2013. Experimental Study of Thermal Performance in Air Gap Membrane Distillation Systems, Including the Direct Solar Heating of Membranes. Desalination. 330: 100-111.

[17] Y. Tian and C. Y. Zhao. 2013. A Review of Solar Collectors and Thermal Energy Storage in Solar Thermal Applications. Appl. Energy. 104: 538-553.

[18] A. Jamar, Z. A. A. Majid, W. H. Azmi, M. Norhafana, and A. A. Razak. 2016. A Review of Water Heating System for Solar Energy Applications. International Communications in Heat and Mass Transfer. 76: 178-187.

[19] M. S. Hossain, R. Saidur, H. Fayaz, N. A. Rahim, M. R. Islam, J. U. Ahamed, and M. M. Rahman. 2011. Review on Solar 
Water Heater Collector and Thermal Energy Performance of Circulating Pipe. Renewable and Sustainable Energy Reviews. 15: 3801-3812.

[20] Z. Wang, W. Yang, F. Qiu, X. Zhang, and X. Zhao. 2015. Solar Water Heating: From Theory, Application, Marketing and Research. Renewable and Sustainable Energy Reviews. 41: 68-84.

[21] M. S. Hossain, A. K. Pandey, J. Selvaraj, N. Abd Rahim, A. Rivai, and V. V. Tyagi. 2019. Thermal Performance Analysis of Parallel Serpentine Flow Based Photovoltaic/Thermal (PV/T) System Under Composite Climate of Malaysia. Appl. Therm. Eng. 153: 861-871.

[22] J. Zhou, H. Ke, and X. Deng. 2018. Experimental and CFD Investigation on Temperature Distribution of a Serpentine Tube Type Photovoltaic/Thermal Collector. Sol. Energy. 174: 735742.

[23] D. Wang, X. Wang, Y. Chen, W. Kang, and Y. Liu. 2019. Experimental Study on Performance Test of Serpentine Flat Plate Collector with Different Pipe Parameters and a New Phase Change Collector. Energy Procedia. 158: 738-743.

[24] D. E. Moudjeber, A. RuizAguirre, D. Ugarte-Judge, $\mathrm{H}$. Mahmoudi, and G. Zaragoza. 2016. Solar Desalination by AirGap Membrane Distillation: A Case Study from Algeria. Desalin. Water Treat. 57: 2271822725.

[25] J. D. Gil, L. Roca, A. RuizAguirre, G. Zaragoza, and M. Berenguel. 2018. Optimal operation of a Solar Membrane Distillation Pilot Plant via Nonlinear Model Predictive
Control. Comput. Chem. Eng. 109: 151-165.

[26] Q. Ma, A. Ahmadi, and C. Cabassud. 2018. Direct Integration of a Vacuum Membrane Distillation Module within a Solar Collector for Small-scale Units Adapted to Seawater Desalination In Remote Places: Design, Modeling \& Evaluation of a Flat-Plate Equipment. J. Memb. Sci. 564: 617-633.

[27] Y. Li and D. Jing. 2017. Investigation of the Performance of Photovoltaic/thermal System by a Coupled TRNSYS and CFD Simulation. Sol. Energy. 143: 100-112.

[28] J. Zhou, Q. Yi, Y. Wang, and Z. Ye. 2015. Temperature Distribution of Photovoltaic Module Based on Finite Element Simulation. Sol. Energy. 111: 97 103.

[29] W. J. Lau and A. F. Ismail. 2009. Theoretical Studies on the Morphological and Electrical Properties of Blended PES/SPEEK Nanofiltration Membranes using Different Sulfonation Degree of SPEEK. $J$. Memb. Sci. 334: 30-42.

[30] W. Wang and B. Laumert. 2014. Simulate a 'Sun' for Solar Research: A Literature Review of Solar Simulator Technology. KTH Royal Institute of Technology. 37.

[31] J. Sarwar, G. Georgakis, R. LaChance, and N. Ozalp. 2014. Description and Characterization of an Adjustable Flux Solar Simulator for Solar Thermal, Thermochemical and Photovoltaic Applications. Sol. Energy. 100: 179-194.

[32] N. M. Mokhtar, W. J. Lau, and A. F. Ismail. 2015. Effect of Feed Temperature on the DCMD 
Performances in Treating Synthetic Textile Wastewater. Adv. Mater. Res. 1113: 776-781.

[33] N. M. Mokhtar, W. J. Lau, A. F. Ismail, W. Youravong, W. Khongnakorn, and K. Lertwittayanon. 2015. Performance Evaluation of
Novel PVDF-Cloisite 15A

Hollow Fiber Composite Membranes for Treatment of Effluents Containing Dyes and Salts Using Membrane Distillation. RSC Adv. 5: 3801138020. 